\title{
A influência do suporte digital na produção escrita de aprendizes de língua inglesa: um estudo sobre Netspeak
}

\author{
The influence of the digital medium in the writing of english learners: a study about \\ Netspeak
}

\begin{abstract}
Resumo: O advento da Internet significou não apenas tecnologia e atualização, mas também o surgimento de novas palavras e expressões características do meio digital (CRYSTAL, 2001). Hoje, as pessoas têm a necessidade de interagir com o computador, o que faz com que o netspeak - termo da língua inglesa para "internetês" - se difunda rapidamente entre aqueles que têm acesso à Internet. Em meados de 2010, para verificar a incidência dessa linguagem na escrita em língua inglesa, foram aplicados questionários, com questões abertas e fechadas, em língua inglesa aos aprendizes de uma escola de idiomas de Uberaba por meio da ferramenta Google docs. O objetivo foi identificar se, mesmo em suporte digital, os alunos se sentiriam à vontade em utilizar a linguagem de rede na escrita desse questionário, que possuía fins acadêmicos. Foram coletadas informações de 14 alunos adolescentes e jovens adultos considerados "nativos digitais" (PRENSKY, 2001), e, em diferentes níveis de proficiência. A análise dos dados apontou que, por se tratar de um contexto acadêmico, alguns entrevistados se intimidaram no uso da linguagem de rede, apesar do suporte pelo qual foi realizado o questionário. Após essa análise, foi agendado, ainda, um chat (situação mais informal que o questionário, porém acondicionado no mesmo suporte) para que fosse possível embasar a suposição de que eles seriam influenciados pelo suporte - suposição confirmada posteriormente.
\end{abstract}

Palavras-chave: netspeak; aprendiz de língua inglesa; Internet.

\begin{abstract}
The advent of the Internet meant not only technology and update, but also the emergence of new words and expressions that are typical from the digital medium (CRYSTAl, 2001). Nowadays, people have the need to interact with the computer, which leads the Netspeak - the English term for "Internetês" in Portuguese - to be spread quickly among those who have Internet access. In mid-2010, to ascertain the incidence of such language in written production in English, some questionnaires with open answers and multiple choice questions - in English were completed by learners of a language school in Uberaba. The tool Google docs was used in order to complete it. The goal was to identify whether, even in digital media, students might feel uncomfortable in using the network language when answering the questionnaire, which had academic purposes. Data were gathered from 14 adolescent students and young adults considered "digital natives" (PRENSKY, 2001), and, in different levels of proficiency. The analysis indicated that, because it was an academic context, some interviewed people felt intimidated to use the network language, despite the medium in which the questionnaire was conducted. After this review, a chat (more informal situation than the questionnaire, but configured in the same medium) was also scheduled, so as to check the assumption that they could be influenced by the medium - which was confirmed after the analyses.
\end{abstract}

Keywords: netspeak; English language learner; Internet.

\footnotetext{
* Aluna do curso de Pós Graduação em Especialização em Ensino de Línguas Mediado por Computador da Universidade Federal de Minas Gerais (UFMG). Graduada em Letras - Português/Inglês pela Universidade Federal do Triângulo Mineiro.
} 


\section{Introdução}

Sabemos que o uso de tecnologias digitais na educação formal consiste numa prática muito frequente hoje em dia. $\mathrm{O}$ s documentos oficiais da área educacional, inclusive os Parâmetros Curriculares Nacionais (BRASIL, 1997) já apontam a união entre escola e computador; os programas de governo incentivam essa ideia e o mesmo está informatizando as escolas públicas.

Não basta visar a capacitação dos estudantes para futuras habilitações em termos das especializações tradicionais, mas antes trata-se de ter em vista a formação dos estudantes em termos de sua capacitação para a aquisição e o desenvolvimento de novas competências, em função de novos saberes que se produzem e demandam um novo tipo de profissional, preparado para poder lidar com novas tecnologias e linguagens, capaz de responder a novos ritmos e processos. (BRASIL, 1997, p. 25)

É indiscutível a necessidade crescente do uso de computadores pelos alunos como instrumento de aprendizagem escolar, para que possam estar atualizados em relação às novas tecnologias da informação e se instrumentalizarem para as demandas sociais presentes e futuras. (BRASIL, 1997, p. 64)

Com esse processo de informatização, espera-se que os estudantes possam ter acesso a toda gama de informações provenientes do meio digital, já que ele está cada vez mais difundido entre eles. Com a necessidade de interação de maneira rápida e eficiente, surgem novas palavras e expressões características do meio digital (CRYSTAL, 2001): o netspeaktermo da língua inglesa para "internetês". Acredito que essa nova linguagem possa até causar uma interferência no comportamento e práticas textuais dos usuários que se comunicam em inglês como língua estrangeira, sendo esse o motivador inicial de minha pesquisa.

Vieira (2005) aponta os vários estudos já realizados e mostra que, até então, a maior ocorrência de pesquisa em gêneros digitais se concentra na aquisição de língua estrangeira (fins) através de recursos digitais (meios). Justifico minha pesquisa pela necessidade de explorar mais o que os aprendizes da língua estrangeira - mais especificamente a inglesa estão produzindo em termos de escrita em ambientes digitais. Devido ao fato de a lingua inglesa ser considerada globalizada (CRYSTAL, 2009) e por ser a língua sobre a qual 
investigamos no grupo de pesquisas $^{1}$ do qual participo, selecionei esta para analisar as ocorrências da linguagem típica da rede.

A realização dessa pesquisa ainda pode ser considerada relevante porque é concebido que o uso da informalidade na produção escrita dos alunos brasileiros nativos digitais deveria ser investigado, tanto as marcas do meio digital encontradas na produção de língua materna, como a de língua estrangeira. Entendo que se faz necessário observar como os alunos lidam com os desvios da produção escrita em língua inglesa considerada como padrão.

Pretendo, com este trabalho, identificar os padrões linguísticos que se repetem na produção escrita em língua inglesa no que se refere à influência do suporte digital. Defendo que pensar as características dos usuários da linguagem da Internet pode auxiliar-nos a compreender os "nativos digitais", nos termos de Prensky $(2001,2006)$, adòlescentes e jovens adultos nativos da era da Internet e comunicação, e como eles se relacionam com o meio digital quando produzem textos nesse suporte. Em outras palavras, pretendo observar as características dos usuários de tal linguagem e as ocorrências de netspeak na sua produção escrita.

Para tanto, primeiramente foram utilizados questionários em língua inglesa a fim de coletar dados e informações mais generalizadas dos participantes. Esses registros me auxiliaram na classificação de sua natividade digital, e posteriormente na análise de ocorrências da linguagem de rede, o netspeak, e algumas reflexões sobre essas ocorrências. Após os procedimentos de análise dessa primeira parte do trabalho, foram solicitados chats com os alunos, também em língua inglesa, para obter mais registros escritos - dessa vez mais informais - e fazer uma comparação entre a escrita de um documento de fins acadêmicos (o questionário) e um bate-papo virtual, ambos no mesmo suporte digital. Analisei como a produção escrita norteada por gêneros poderia intimidar e/ou fornecer oportunidade para a utilização de netspeak, ou seja, como o espaço discursivo do questionário e do chat pode ser influenciado pelo suporte digital.

A partir da fundamentação teórica e metodologia, descreverei os usuários nativos digitais que buscamos para a realização dessa pesquisa. Aponto que uma das características desses indivíduos é a utilização de netspeak. Essa linguagem foi propiciada pelo contato com $\mathrm{o}$ artefato tecnológico, levando-nos a observar como o suporte digital pode influenciar a

\footnotetext{
${ }^{1}$ Grupo de Estudos da Linguagem e Educação Digital (GELED) da Universidade Federal do Triângulo Mineiro, que tem por objetivo gerar pesquisas com foco na utilização de recursos tecnológicos no contexto de ensino e aprendizagem de língua inglesa.
} 
escrita em diferentes momentos - no gênero questionário e no gênero chat. Para concluir, retomarei os pontos mais relevantes obtidos da pesquisa e apresentarei algumas considerações finais e sugestões para estudos posteriores.

\section{Fundamentação teórica}

Nesta seção, trago alguns conceitos que serviram de base teórica para esta pesquisa. Primeiramente, conceituarei os aprendizes que são o foco de nossa atenção e que vêm sendo considerados parte de uma nova geração intitulada digital. Em segundo lugar, explicarei uma das práticas escritas típicas dessa geração e de todos aqueles que estão habituados a utilizar comunicação instantânea na Internet: o netspeak. Na sequência, discorrerei um pouco sobre o suporte digital, e para finalizar, farei uma conclusão sobre a questão dos gêneros e suas influências nas práticas escritas comuns no meio digital.

Podemos considerar o indivíduo que lida com ferramentas tecnológicas de maneira autônoma um "nativo digital", nos termos de Prensky (2001). Para o autor, eles podem ser assim considerados pelo fato de serem "falantes nativos" da linguagem digital dos computadores, vídeo games e da Internet, nasceram na era digital e tiveram seu primeiro contato com as tecnologias bem cedo. Além disso, são capazes de realizar várias tarefas no computador simultaneamente, utilizam o meio digital para realizar atividades diárias, como pesquisas escolares. Nas palavras do autor,

Os nativos digitais estão acostumados a receber informações muito rapidamente. Eles gostam do processamento paralelo e da multitarefa. Eles preferem gráficos antes do texto, e não o contrário. (...) Eles trabalham melhor quando conectados em rede. Eles progridem com gratificações instantâneas e recompensas frequentes. Eles preferem jogos ao invés de "trabalho sério". ${ }^{2}$ (PRENSKY, 2001, p. 2, tradução minha)

Aquele indivíduo desatualizado tecnologicamente, que teve um contato tardio com essas ferramentas e que não estão inseridos nos princípios da citação acima pode ser considerado um "imigrante digital", segundo esse mesmo autor.

Prensky (2001) acredita também que é possível identificar esses nativos digitais, inclusive pela sua linguagem. É interessante pontuar que a linguagem típica utilizada pelos nativos digitais coincide com a linguagem comum na web. Com o surgimento da Internet,

\footnotetext{
${ }^{2}$ Essa e todas as outras traduções feitas neste artigo são de minha responsabilidade.
} 
apareceram também as palavras características desse meio - tanto as dicionarizadas, com função denominativa, quanto os neologismos que apenas representam certas expressões. Crystal (2001) chama esses neologismos de netspeak.

Segundo Crystal (2001, p. 17), podemos chamar de netspeak uma alternativa para a comunicação mediada por computador. Esta é uma linguagem que incorpora neologismos diversos, sinais tipográficos, os chamados emoticons e os "desvios" da norma culta ortográfica da língua, como por exemplo, a falta de pontuação. Há nesta linguagem uma tendência em tomar o ato de fala com base na produção escrita, pois os usuários se adaptam às operações instantâneas e automáticas de conversação. Ou seja, eles se apropriam de uma linguagem oral, que de modo geral tem muita expressividade, e transferem-na para a escrita. Desse modo, o texto produzido por eles se aproxima bastante dessa representação oral. Alguns dos exemplos dessas expressões abreviadas são "ic" (I see), “cul8r" (see you later), “f2f” (face to face); os emoticons / smiles ( $:-;:)$ ) (CRYSTAL, 2001).

Crystal (2001) dá uma definição a essa variação linguística para ajudar-nos a compreender como se dá o processo de formação de uma expressão do netspeak. Para o autor, essa variação é um sistema de expressões linguísticas cujo uso é governado por fatores situacionais. Esses fatores são culturais, regionais, dialetais, de fala e de escrita, dentre outros. Ele também enumera as características de formação dessas variedades. São elas:

- gráficas: a apresentação e organização geral da linguagem escrita, como design de páginas, manchete e notícia;

- ortográfica (grafológica): sistema escrito da linguagem escrita, como o alfabeto, a letra maiúscula, a ortografia, a pontuação;

- gramatical: possibilidades da sintaxe e morfologia, como a estrutura da frase e a ordem das palavras;

- lexical: o vocabulário da linguagem, expressões;

- de discurso: organização estrutural do texto, como coerência, relevância, progressão de ideias, estrutura de parágrafos;

- fonética: características audíveis da língua falada, como a fala, o canto; e

- fonológica: sistema sonoro de determinada língua, como os sons, as vogais, a entonação, a tonicidade e o sotaque.

A partir dessas descrições, o autor ainda afirma que as características gramaticais, lexicais e de discurso têm um grande papel em todas as variedades linguísticas faladas, assim 
como nas escritas.

Pelo desvio da norma culta, já citado anteriormente, observamos certo grau de informalidade na comunicação escrita típica do meio digital, e à medida que a Internet se tornou acessível à grande parte da população mundial, o netspeak também se popularizou. No contexto escolar, por exemplo, isso se deve à larga utilização do computador e a frequência com que os alunos visitam sites de comunicação em língua inglesa, como os jogos on-line e redes sociais. Os seus usuários possuem, então, a ferramenta necessária - o computador - para difundi-lo, assim como aprendê-lo a partir da prática efetiva de conteúdos abstratos.

O netspeak já está pré-situado em um contexto tecnológico de interação via rede em que os usuários precisam tornar o uso da língua mais rápida, pois a comunicação em tempo real o requer. Assim, unindo o uso do netspeak aos objetivos de comunicação instantânea, o internauta possui meios eficientes de troca de informações. Podemos pensar essa relação do usuário com o artefato tecnológico (o suporte) e as consequentes adaptações da prática escrita no meio digital à luz da abordagem ecológica, já que é nesse meio que o usuário encontra o espaço propício para tal prática.

Van Lier (2004, p. 3, tradução minha) afirma que "Uma vez que a ecologia estuda os organismos e as suas relações com o ambiente, a ecologia é uma forma contextualizada ou situada de pesquisa", e a partir da interação entre usuário e ambiente é que se desenvolve a motivação para a aprendizagem. A partir desse conceito, é construída a ideia de que o ambiente físico, repleto de informações, é utilizado pelo usuário para alcançar objetivos previamente determinados por ele. Podemos considerar, então, o meio digital como um espaço no qual o objetivo da interação entre os usuários pode ter sucesso, já que a motivação de comunicar-se contribui para a aprendizagem da nova linguagem típica da Internet sobre a qual discorremos: o netspeak. Parece-me imprescindível considerar o suporte como fator determinante para essa prática textual, já que seria atípico que tal prática acontecesse, por exemplo, em práticas textuais que se utilizam do papel.

Nesse sentido, defendo que o intuito de escolher o suporte digital para a minha pesquisa foi o fato de acreditar que o netspeak é uma prática comum no meio digital e encontrado nos gêneros emergentes da Internet, os gêneros digitais. Faz-se necessário, assim, definir o que é compreendido por gênero, pois esse conceito é útil para sustentar a realização do trabalho.

Tomamos por gênero as "práticas enunciativo-discursivas (...) mediadas por 
enunciados" (COSTA, 2009). Bazerman (2009) esclarece que eles são categorias sóciohistóricas que estão sempre em mudança, são dinâmicos. Bazerman (2007) mostra como o gênero é situado historicamente de acordo com as cargas sociais, afetivas, de significado, enfim, cargas subjetivas que motivam a produção de enunciados. Em dada época histórica, um indivíduo produz enunciados correspondentes a essa época. Atualmente, o indivíduo produz enunciados correspondentes à era das tecnologias digitais de informação e comunicação. Essa característica nos remete às ferramentas tecnológicas digitais - no caso, o computador e a Internet.

No caso do gênero digital, uma das características que emergem na relação com o novo meio é o netspeak. Como já for citado anteriormente, ela se baseia no ato de fala, que é utilizado para a produção escrita. Bakhtin (1953 apud COSTA, 2009) denomina o ato conversacional como "um dos gêneros primários da oralidade humana" por este ter aparecido primeiro, "é primitivo, original" (p. 16). Um gênero secundário seria aquele que toma o ato conversacional do cotidiano e o introduz em uma esfera mais complexa, como é o caso de diálogos em entrevistas, histórias. Para ilustrar, o gênero secundário do diálogo em chat tomou o gênero primário - o da oralidade humana - como um mecanismo de interação imediata entre interlocutores. Nesse sentido, as práticas escritas da Internet são consideradas novos gêneros secundários, pelo fato de as conversas cotidianas circularem em um novo suporte de comunicação.

Os gêneros estão presentes nas mais diversas esferas comunicativas e incorporam características próprias de acordo com a intenção, tempo histórico e cultura do enunciador. Entretanto, de acordo com Costa (2009), a definição de cada gênero é bastante limitada, já que são todos diferentes, porém com elementos semelhantes entre eles. Os gêneros emergentes como os digitais causam ainda mais polêmicas em se tratando de classificações. Eles podem funcionar

ora como gêneros ora como suportes de texto, como o cartaz, o banner, o outdoor, etc. Outros ainda podem ser ambientes, ou seja, domínios de produção e processamento de textos onde emergem novos gêneros textuais aí abrigados ou condicionados. (COSTA, 2009, p. 12)

Mesmo compreendendo que os gêneros demonstram prototipicidade e não classificações fechadas e estanques, é importante pontuar o que é entendido minimamente como questionário e chat, os dois gêneros que selecionei para a condução dessa pesquisa. 
Costa (2009) define o questionário como:

conjunto, relação ou sequência, oral ou escrita, de perguntas ou questões feitas para diversos fins: para servir de guia, por exemplo, a uma investigação (v.), a uma entrevista (v.), a um trabalho (v.) de pesquisa escolar, etc. (COSTA, 2009, p. 173)

e o chat como:

conversa/conversação (v.) informal teclada em tempo real através da Internet, portanto virtual. Caracteriza-se como uma escrita abreviada (...). Recursos já existentes (sinais de pontuação, abreviações, elementos gráficos, maiúsculas, etc.) são reutilizados pelos usuários para o desenvolvimento do falar-escrito ou da escrita-oralizada, de caráter híbrido, que caracteriza os chats (bate-papo) da Internet, uma intenção bastante informal. (COSTA, 2009, p. 62)

Uma das diferenças entre os dois gêneros selecionados é que enquanto o questionário é típico do meio impresso, o chat, mesmo tendo sua origem no gênero primário da conversação, é conhecido tipicamente como um gênero digital emergente. Dentro dessa pesquisa, o fato de o documento questionário estar situado no meio digital possibilita que a produção escrita dos alunos também tenha o estilo e estrutura textual correspondentes do meio digital, assim como o chat. Assim, os dois gêneros em questão - o questionário e o chat - podem apresentar as mesmas características da linguagem de rede digital pelo fato de estarem nesse suporte.

\section{Metodologia}

Esta pesquisa é classificada como de base mista - qualitativa e quantitativa. É qualitativa por estar embasada nos moldes da análise de dados e a interpretação dos mesmos. De acordo com Denzin e Lincoln (2006, p. 17), “a pesquisa qualitativa envolve o estudo do uso e a coleta de uma variedade de materiais empíricos [...] que descrevem momentos e significados rotineiros e problemáticos na vida dos indivíduos”. Portanto, possui caráter de uma prática que situa o pesquisador no contexto investigado. Ou seja, para construir significados, a pesquisa qualitativa depende de elementos externos, de mundo. Os conhecimentos de ferramentas tecnológicas, da linguagem do netspeak, de ações intrínsecas e rotineiras do ser humano, como a capacidade de comunicação, norteiam esse percurso de investigação. A pesquisa é também quantitativa, apesar de que não é meu objetivo trazer dados quantitativos para embasar-nos estatisticamente. Mas os números nos permitem 
observar em quais grupos de indivíduos - a serem descritos posteriormente - houve maior ocorrência da linguagem que investigamos.

A ideia de realizar esse estudo em uma escola de idiomas se deu, primeiramente, pelo fato de eu buscar evidências na produção escrita, prática que acredito que seja mais comum em um instituto de ensino de idiomas do que em uma escola de ensino regular, pública ou privada. Essa curiosidade está embasada também nos moldes da abordagem processual da escrita em língua inglesa que, segundo Ferreira (2011), "se concentra no produto", que é o texto em LE. Além disso, como professora nessa instituição, estava em contato diário com alunos de diferentes estágios da língua inglesa e tive a possibilidade de divulgar a pesquisa em todas as salas de aula e pedir a colaboração dos alunos. Após a solicitação da autorização da escola, dei procedência à solicitação da autorização dos partícipantes por meio de um “Termo de Consentimento Livre e Esclarecido".

Coletei 50 endereços de e-mail de alunos, para os quais enviei o questionário. Apenas 14 pessoas se dispuseram a participar, sendo elas: 2 alunos do estágio básico de língua inglesa (que denominarei grupo 1); 8 alunos do estágio intermediário (grupo 2); e 4 alunos do estágio avançado (grupo 3), todos eles estudantes dessa escola de idiomas de Uberaba.

Como ferramenta para a aplicação desse questionário foi utilizado o "Google docs". De acordo com o site Wikipédia, este programa é um

pacote de aplicativos do Google (...). Funciona totalmente on-line diretamente no browser. (...) Alguns dos recursos mais peculiares são a portabilidade de documentos, que permite a edição do mesmo documento por mais de um usuário e o recurso de publicação direta em $b l o g$.

O questionário - constituído em sua maioria por questões fechadas e algumas abertas - foi criado a partir desse programa para facilitar o recebimento do mesmo, a troca de informações, e dar ao trabalho características e ferramentas úteis para a análise, já que se trata do meio digital. Julguei ser pertinente aplicá-lo nesse suporte, ao invés do papel, pois o netspeak é uma linguagem característica desse meio. Sobre a redação, deixei claro aos alunos que não se tratava de uma avaliação, e que eles teriam liberdade em se expressar, sem a preocupação de "saber escrever bem em inglês".

Desse questionário, foram extraídas apenas as questões válidas para a pesquisa. Essas questões puderam me auxiliar na identificação dos nativos digitais e traçar perfis de grupos de acordo com idade e sexo. Essa primeira observação foi necessária, pois na categoria de jovens 
adultos talvez essa designação variasse de acordo com as idades e oportunidades de acesso às tecnologias.

Após a aplicação do questionário, foram consideradas as hipóteses de, ou os colaboradores se sentirem intimidados em usar o netspeak ao responder as perguntas ou não saberem usá-lo. Essas constatações se devem ao fato de eles responderem a uma das questões do questionário como sendo usuários desse tipo de linguagem, mas não o fizeram na redação do questionário. Era preciso obter mais registros, dessa vez em contexto mais informal, para constatar essas possibilidades. Então, em uma segunda etapa de coleta de registros escritos, propus um chat em Língua Inglesa.

Pedi aos 14 alunos que entrassem em contato, individualmente, por meio do MSN Messenger, um programa de mensagens instantâneas, um chat room. Esclareci a eles que precisava de apenas mais algumas informações pessoais para a pesquisa que estava conduzindo. Mesmo após obter evidências de uso de netspeak, continuamos a conversar sobre outros assuntos relacionados à escola na qual coletamos os dados.

\section{Análise}

Como apontado anteriormente, separei os participantes em grupos: estudantes do estágio básico de língua inglesa - grupo 1; estudantes do estágio intermediário de língua inglesa - grupo 2; e estudantes do estágio avançado de língua inglesa - 3. Na análise primária - a do questionário - foram consideradas as informações de todos os participantes, a fim de classificá-los quanto ao grau de familiaridade com o meio digital. Selecionei algumas questões que contribuíssem nessa classificação.

As primeiras perguntas analisadas consistem em questões fechadas. Elas serviram para verificar a média de ocorrência do netspeak entre os grupos, e se os alunos realmente se encaixariam na classificação de nativos digitais. 


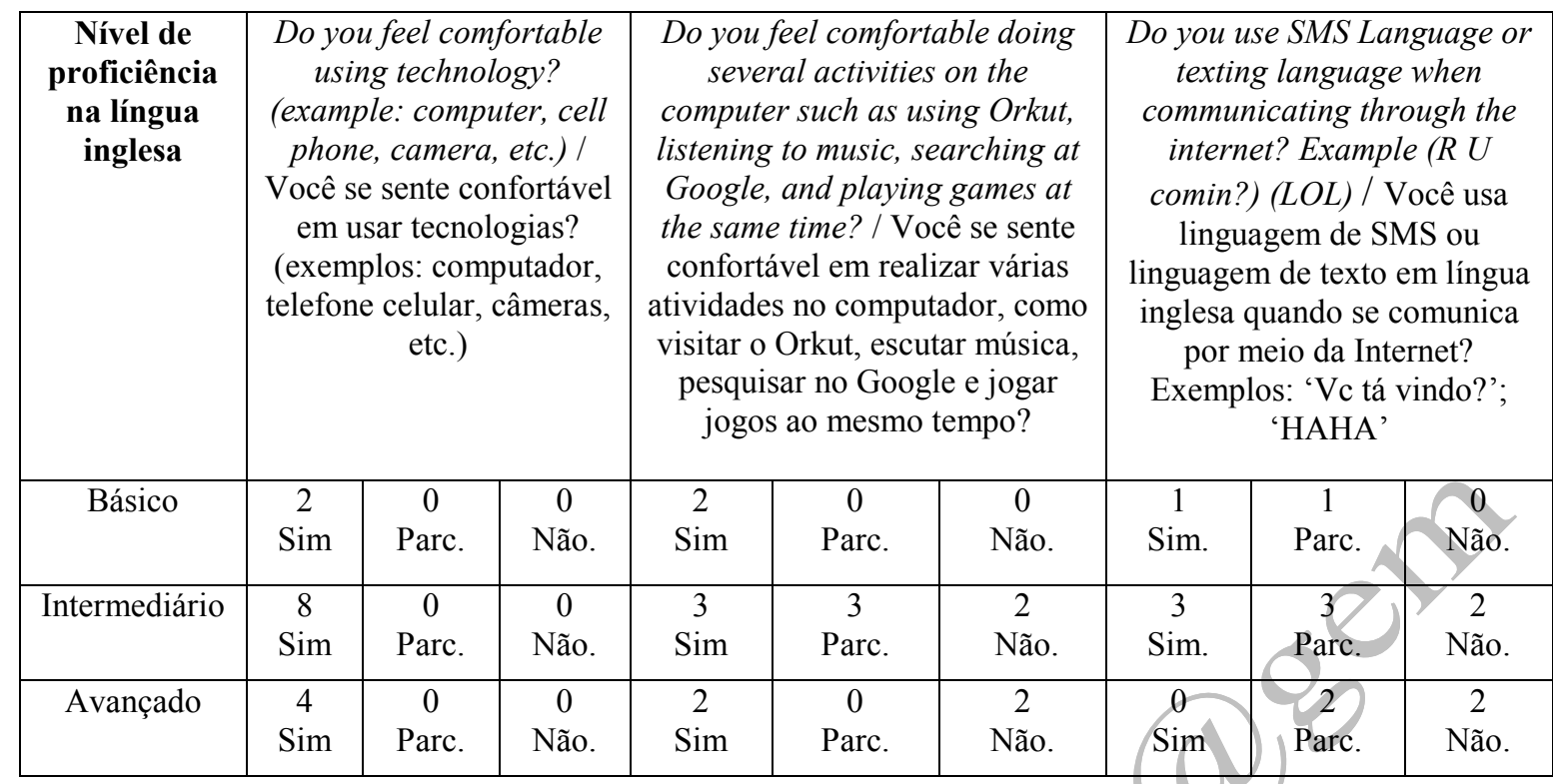

\begin{tabular}{|c|c|c|c|c|c|c|}
\hline $\begin{array}{c}\text { Nível de } \\
\text { proficiência } \\
\text { na língua } \\
\text { inglesa }\end{array}$ & \multicolumn{3}{|c|}{$\begin{array}{l}\text { Does the technology you use } \\
\text { influence your learning } \\
\text { process of a foreign } \\
\text { language? / A tecnologia que } \\
\text { você utiliza influencia o seu } \\
\text { processo de aprendizagem de } \\
\text { uma lingual estrangeira? }\end{array}$} & \multicolumn{3}{|c|}{$\begin{array}{l}\text { Are you afraid of tying different } \\
\text { commands, in/with technological } \\
\text { things, in order to reach your } \\
\text { destination? / Você tem receio } \\
\text { de usar comandos diferentes } \\
\text { em/com ferramentas } \\
\text { tecnológicas com o objetivo de } \\
\text { alcançar seus objetivos? }\end{array}$} \\
\hline Básico & $\begin{array}{c}2 \\
\text { Sim }\end{array}$ & & $\begin{array}{c}0 \\
\text { Não. }\end{array}$ & $\begin{array}{c}0 \\
\text { Sim }\end{array}$ & $\begin{array}{c}1 \\
\text { Parc. }\end{array}$ & $\begin{array}{c}1 \\
\text { Não. }\end{array}$ \\
\hline Intermediário & $\begin{array}{c}8 \\
\text { Sim }\end{array}$ & $\begin{array}{c}0 \\
\text { Parc }\end{array}$ & $\begin{array}{c}0 \\
\text { Não. }\end{array}$ & $\begin{array}{c}2 \\
\text { Sim }\end{array}$ & $\begin{array}{c}4 \\
\text { Parc. }\end{array}$ & $\begin{array}{c}2 \\
\text { Não. }\end{array}$ \\
\hline Avançado & $\begin{array}{c}4 \\
\text { Sim }\end{array}$ & $\begin{array}{c}0 \\
\text { Parc }\end{array}$ & $\begin{array}{c}0 \\
\text { Não. }\end{array}$ & $\begin{array}{c}2 \\
\text { Sim }\end{array}$ & $\begin{array}{c}1 \\
\text { Parc. }\end{array}$ & $\begin{array}{c}1 \\
\text { Não. }\end{array}$ \\
\hline
\end{tabular}

De acordo com as respostas do quadro acima, observamos que todos os alunos dos 3 grupos alegam utilizar artefatos tecnológicos com autonomia. Quanto à segunda pergunta, a maioria dos participantes dos 3 grupos relatou não ter problemas em realizar várias tarefas simultâneas no computador, completamente ou parcialmente. Na pergunta sobre a utilização do netspeak, percebi maior ocorrência no grupo 2, já que considero a resposta "parcialmente" como positiva, pois ela não descarta o uso dessa linguagem. Em seguida, foi unânime a opinião de que as tecnologias influenciam o processo de aprendizagem da língua estrangeira. Por último, indaguei sobre o receio de experimentar comandos diferentes. O grupo 1 relatou ter menos problemas com esse tipo de prática do que os outros grupos. Os grupos 2 e 3 têm mais resistência a utilizar novos comandos no computador. 
Como podemos notar, as informações de cada grupo variam de acordo com o nível de proficiência da língua inglesa. Porém, todos possuem características de um nativo digital, ou por afirmarem que usam o netspeak, ou por ter familiaridade com as tecnologias, ou por ter a habilidade de realizar múltiplas tarefas simultaneamente.

$\mathrm{Na}$ análise linguística das perguntas abertas, percebi a utilização do netspeak em apenas dois participantes - um do grupo 1 e outro do grupo 3. Sobre a utilização de recursos tecnológicos na aplicação das aulas de inglês por ela assistidas, a aluna Maria ${ }^{3}$ de 19 anos, pertencente ao grupo 3, respondeu nos seguintes termos:

Hun, no, my teachers have never used this kind of applications to give classes. ${ }^{4}$

Na questão Why have you decided to learn a foreign language? $?^{5}$, a aluna redigiu sua resposta da seguinte forma:

I decided to learn english because I wanned to know what the people in the movies and the songs I hurd were talking about. ${ }^{6}$

A palavra grifada "Hun" nos dá exemplos de uma variação linguística por caracterização fonética. Ela também se encaixa na classificação de palavras chamadas "sinais de reação"7 (CRYSTAL, 2001, p. 40), que indicam mais espontaneidade. As palavras "wanned" e "hurd" são exemplos de palavras cuja variação é ortográfica. Como podemos observar nos grifos, a primeira aluna usa o netspeak de maneira mais autônoma, na grafia das palavras. Acredito que isso se deva ao fato de ela cursar um estágio mais avançado de Língua Inglesa - um curso preparatório para um exame internacional da língua. Por esse motivo, percebo mais segurança no uso dos desvios da norma padrão.

A aluna Marta de 13 anos de idade - pertencente ao grupo 1 - apresentou marcas de netspeak em mais momentos. O primeiro deles, na questão abaixo:

Do you belong to any social network such as Messenger, Orkut, and etc? Do you usually go to these sites? How often do you go? ${ }^{8}$

Marta responde:

Yes. Ooh, maaany, many times. If I can, I go everyday, and everytime, but i can't.

\footnotetext{
${ }^{3}$ Todos os nomes são fictícios.

4 Tradução: "Hm, não, meus professores nunca usara esse tipo de aplicativos para dar aulas"

${ }^{5}$ Tradução: "Por que você decidiu aprender uma língua estrangeira?"

${ }^{6}$ Tradução: "Eu decidi aprender inglês porque eu queria saber o que as pessoas dos filmes e músicas que eu ouvia estavam falando."

${ }^{7}$ Nossa tradução de "reaction signals"

${ }^{8}$ Tradução: "Você pertence a alguma rede social como Messenger, Orkut, etc? Você visita frequentemente esses sites? Com que frequência você os visita?"
} 


$$
=1^{9} \text {. }
$$

O segundo momento foi percebido na pergunta

"Choose two of these applications and tell us some positive or negative experience that you have ever had with them. Among these experiences, try to remember if one of them involved the use of a language that is not yours. Explain $^{10}$.

Nela, a aluna afima:

Once, I was in the computer, and I the MSN. then I meet people in France, so these people talk me, but I didn't understand nothing she talk, so called my mother for me explain that words.. and she explains for me ***. I just remember this $=1^{11}$.

O terceiro questionamento diz:

Why have you decided to learn a foreign language? Which situation (artistic, professional, and/or academic) motivates or motivated you to learn a foreign language? ${ }^{12}$

A aluna justifica:

Because I liiike english, i like very much, so decided learn for my life same (: I intend use for my job in the future, whatever ${ }^{13}$.

Marta cursa o nível básico de Língua Inglesa e, apesar de conseguir expressar-se bem, não possui tanta segurança em termos de linguagem quanto Maria. Por isso ela usa mais emoticons $(=\backslash)$ e sinais de reação - como "Ooh", "maaany" e "liiike" - do que a primeira aluna que usou o desvio na ortografia das palavras.

\footnotetext{
${ }^{9}$ Tradução: Ah, muuuitas, muitas vezes. Se eu posso, visito todos os dias, a todo momento, mas eu não posso. $=$ "”

${ }^{10}$ Tradução: "Escolha dois desses aplicativos e conte-nos alguma experiência positiva ou negativa que você já teve com os mesmos. Entre essas experiências, tente lembrar se alguma delas envolveu o uso de uma língua que não é a sua. Explique”.

${ }^{11}$ Tradução: "Uma vez, eu estava no computador, e no MSN. Então eu conheci pessoas da França, então essas pessoas falaram comigo, mas eu não entendi nada do que elas diziam, então eu chamei a minha mãe para me explicar aquelas palavras.. e ela me explicou *_*. Eu só me lembro disso $=$ "”

12 Tradução: "Por que você decidiu aprender uma língua estrangeira? Que situação (artística, profissional e/ou acadêmica) te motiva ou motivou a aprender uma língua estrangeira?".

${ }^{13}$ Tradução: "Porque eu gooosto de inglês, eu gosto muito, então eu decidi aprender para a minha vida mesmo (: Eu pretendo usá-la no meu trabalho no futuro, ou o que seja".
} 
Sendo assim, encontramos o netspeak apenas na escrita de uma participante do grupo 1 e outra do grupo 3. Contudo, é relevante citar dentre todos os entrevistados - salvo uma participante do grupo 2 -, a falta do uso de letras maiúsculas em começo de frase, uma marca ortográfica ou grafológica, segundo Crystal (2001) e também a falta do apóstrofo na contração de verbos auxiliares e palavras de negação, como o "don't" foram constatadas. Isso nos mostra marcas de informalidade na escrita, que são comuns no netspeak, mas também comum nas práticas escritas informais no papel.

Percebendo a contradição dessas informações, decidi solicitar um chat em língua inglesa para confirmar se eles usam o netspeak quando escrevem em suporte digital e se os alunos se sentiram intimidados em usá-lo em um documento para fins acadêmicos.

Nesse chat, todos os alunos utilizaram mais variações, como "no why?" (classificada como variação ortográfica); "language SMS" (classificada como variação lexical - por ter vocabulário próprio da linguagem - e variação gramatical - pela ordem substantivo/adjetivo); e "hmm" (classificada como fonética). Podemos verificar que os alunos, que haviam respondido no questionário que usavam o netspeak, agora não o omitiram no chat. Por isso, indaguei a respeito da não utilização do mesmo anteriormente. Bruno disse que tomou mais cuidado, pois pensava que "the questionnaire is more formal ${ }^{14 "}$. Miriam também respondeu o mesmo: "ahh mas aqui e informal nee". Apesar de Marta tê-lo utilizado no questionário, no chat ela diz: "achei que não podia :" "

Após esse bate-papo, percebo que realmente os alunos usam a linguagem de rede ao praticar a escrita no suporte digital. Pude contrastar a modalidade escrita do gênero 1 - o questionário - e do gênero 2 - o chat. Além de o chat estar situado em comunicação em tempo real, ele quase não teve relação com o contexto formal do questionário, exceto quando perguntei aos alunos quais eram os outros tipos de emoticons e abreviações que eles usavam.

\section{Considerações finais}

A pesquisa teve como motivador inicial a análise da ocorrência da linguagem de rede em língua inglesa, o netspeak, em contexto digital na produção de aprendizes desse idioma. Como esta não é a sua língua materna, seria interessante verificar como os alunos a utilizam e se possuem autonomia na produção dos seus desvios. Pudemos identificar a utilização de

\footnotetext{
${ }^{14}$ Tradução: “o questionário é mais formal”
} 
netspeak em duas das participantes e essa prática se diferenciou em termos da idade e do nível de proficiência de inglês delas.

Durante a análise de dados, surgiu uma segunda pergunta de pesquisa: se os participantes relataram que usam o netspeak, por que omitiram essa linguagem na redação do questionário? Partiu disso a proposição do chat para fornecer argumentos sólidos de que o gênero influenciou os alunos na utilização do netspeak.

Posso assim concluir que os participantes da pesquisa - nativos digitais - usam a linguagem de rede em inglês - o netspeak - no suporte digital, mas essa prátíca é parcialmente ditada de acordo com o gênero em que produzem, pois a ocorrência de tal desvio foi observada em maior escala no chat que no questionário. Percebemos que, nos variados níveis de conhecimento da língua, foi possível a utilização da linguagem informal, sob aspectos diferentes. Afirmo também que a maioria deles se sentiu intimidada em usar o netspeak pelo fato de ser esse um questionário para fins de pesquisa acadêmica, por ter sido solicitado em ambiente escolar, no qual os alunos depositam um grau de "seriedade", ou por talvez não dominar essa modalidade de escrita em LE. Apesar disso, a marca da informalidade percebida pela falta de pontuação me permitiu observar a influência do suporte digital na escrita desses alunos. A incidência do uso desse suporte fez com que o uso da linguagem de rede pelos usuários se tornasse involuntário, induzindo-os à não utilização de algumas marcas da norma culta da língua, como foi o caso da falta do apóstrofo.

Foram várias as limitações de pesquisa. A primeira delas foi a dificuldade em conseguirmos o parecer do Comitê de Ética em Pesquisa da instituição. Tive um período muito curto de tempo para as pesquisas de campo. Houve também uma resistência da participação dos alunos de estágios básicos da língua inglesa. Eles não queriam colaborar talvez por acreditarem que não saberiam redigir em norma culta as respostas dissertativas. A segunda limitação também se deve pela falta de interesse dos alunos sobre a pesquisa. Foram coletados e-mails de 50 alunos, mas obtivemos resposta de apenas 14 deles. A necessidade de outra fonte de análise - o chat - também foi crucial. Sem o chat, minha hipótese de os alunos se sentirem intimidados no uso do netspeak no questionário não poderiam ser comprovadas apenas por esse documento.

A partir das observações feitas sobre o uso do netspeak pelas alunas Maria e Marta, sugiro a retomada das diferenças dessas variações para estudos posteriores. Esse tópico é bastante válido, uma vez que tal característica foi observada em um caso isolado. Um estudo 
mais abrangente confirmaria ou não a ideia da influência do nível linguístico na produção da variação. É pertinente apontar também que há a necessidade de explorar mais os gêneros em suportes digitais em relação à produção escrita dos usuários, e não apenas a compreensão textual.

\section{Referências}

BAZERMAN, C. Escrita, gênero e interação social. São Paulo: Cortez, 2007.

Gêneros textuais, tipificação e interação. DIONÍSIO, A. P.; HOFFNAGEL, J. C. (Org.). Tradução e adaptação de Judith Chambliss Hoffnagel. 3 ed. São Paulo: Cortez, 2009.

BRASIL. Parâmetros Curriculares Nacionais: Introdução aos Parâmetros Curriculares Nacionais. Brasília: MEC/SEF, 1997.

COSTA, S. R. Dicionário de gêneros textuais. 2 ed. Belo Horizonte: Autêntica editora, 2009.

CRYSTAL, D. Language and the Internet. Cambridge, Cambridge University Press. 2001.

CRYSTAL, D. Uma revolução sem gramática. Educar para crescer. 2009. Disponível em: $<$ http://educarparacrescer.abril.com.br/aprendizagem/revolucao-gramatica471614.shtml>.Acesso em: 17 de junho de 2010.

DENZIN, N; LINCOLN, Y. O planejamento da pesquisa qualitativa: teorias e abordagens. 2 ed. Porto Alegre: Artmed, 2006.

FERREIRA, M. M.. O livro didático importado em inglês e o ensino da escrita. Trabalhos em Linguística Aplicada, vol. 50 no.1, São Paulo, Jan/Jun 2011.

PRENSKY, M.. Digital natives, digital immigrants. On the horizon, v. 9, n. 5, 2001.

VAN LIER, L. The Ecology and Semiotics of Language Learning: a sociocultural perspective. Dordrecht: Kluwer Academic Publishers, 2004.

VIEIRA, I. L. Tendências em pesquisas em gêneros digitais: focalizando a relação oralidade / escrita. In: ARAÚJO, J. C.; BIASI-RODRIGUES, B. (Org.). Interação na Internet: novas formas de usar a linguagem. Rio de Janeiro: Lucerna, 2005. P. 244-267.

WIKIPEDIA. http://pt.wikipedia.org/wiki/Google_docs>, acessado em 07/11/2010

Artigo recebido em: 15.10 .2012

Artigo

aprovado

em:

18.12 .2012 